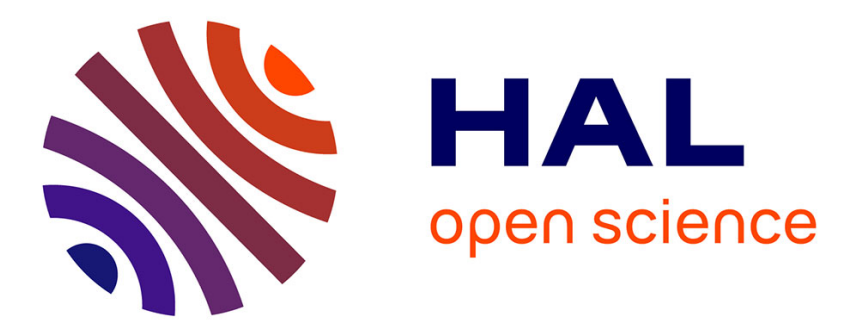

\title{
Novel roles of the Unfolded Protein Response in the control of tumor development and aggressiveness
}

Nicolas Dejeans, Kim Barroso, Martin E. Fernandez-Zapico, Afshin Samali, Eric Chevet

\section{- To cite this version:}

Nicolas Dejeans, Kim Barroso, Martin E. Fernandez-Zapico, Afshin Samali, Eric Chevet. Novel roles of the Unfolded Protein Response in the control of tumor development and aggressiveness. Seminars in Cancer Biology, 2015, 33, pp.67-73. 10.1016/j.semcancer.2015.04.007 . hal-01150385

HAL Id: hal-01150385

https://hal-univ-rennes1.archives-ouvertes.fr/hal-01150385

Submitted on 12 Nov 2015

HAL is a multi-disciplinary open access archive for the deposit and dissemination of scientific research documents, whether they are published or not. The documents may come from teaching and research institutions in France or abroad, or from public or private research centers.
L'archive ouverte pluridisciplinaire HAL, est destinée au dépôt et à la diffusion de documents scientifiques de niveau recherche, publiés ou non, émanant des établissements d'enseignement et de recherche français ou étrangers, des laboratoires publics ou privés. 


\section{Novel roles of the Unfolded Protein Response in the control of tumor development and aggressiveness}

Nicolas Dejeans ${ }^{1,2}$, Kim Barroso ${ }^{1,2,3,4,5}$, Martin E. Fernandez-Zapico ${ }^{3}$, Afshin Samali ${ }^{6}$ and Eric Chevet $^{1,2,4,5^{*}}$

${ }^{1}$ INSERM, UMR-1053, Team “Endoplasmic Reticulum Stress and Cancer”, 33000 Bordeaux, France; ${ }^{2}$ Université de Bordeaux, 33000 Bordeaux, France; ${ }^{3}$ Schulze Center for Novel Therapeutics, Division of Oncology Research, Mayo Clinic, Rochester, MN, USA ; ${ }^{4}$ ER440 Université Rennes 1, “Oncogenesis, Stress, Signaling”, Rennes, France; ${ }^{5}$ Centre de Lutte Contre le Cancer Eugène Marquis, Rennes, France; ${ }^{6}$ Apoptosis Research Centre, School of Natural Sciences, NUI Galway, Galway, Ireland ;

*correspondence to EC: $\underline{\text { eric.chevet } @ \text {,inserm.fr }}$ 


\section{Abstract}

The hallmarks of cancer currently define the molecular mechanisms responsible for conferring specific tumor phenotypes. Recently, these characteristics were also connected to the status of the secretory pathway, thereby linking the functionality of this cellular machinery to the acquisition of cancer cell features. The secretory pathway ensures the biogenesis of proteins that are membrane-bound or secreted into the extracellular milieu and can control its own homeostasis through an adaptive signaling pathway named the Unfolded Protein Response (UPR). In the present review, we discuss the specific features of the UPR in various tumor types and the impact of the selective activation of this pathway on cell transformation, tumor development and aggressiveness.

Keywords: endoplasmic reticulum, cancer, stress, tumor, EMT 


\section{Introduction}

Tumor phenotypes including development and aggressiveness features can dramatically vary depending on the origin of tumor cells and context. The hallmarks of cancer defined by Hanahan and Weinberg [1] have helped to define these characteristics, which were also connected to the status of the secretory pathway (SP) $[2,3]$. As a consequence this essential cellular component has taken significant importance in the acquisition of cancer cell features. The SP ensures the biogenesis of proteins that are membrane-bound or secreted into the extracellular milieu. It is well accepted that approximately one-third of the polypeptides synthesized by a cell, enter the endoplasmic reticulum (ER), the first compartment of the SP $[2,3]$. However, the quantity of proteins entering the secretory pathway fluctuates, depending on the cell physiology, function and specific microenvironment. For instance, the synthesis of antibodies, extracellular matrix proteins, membrane receptors or secretory cyto/chemokines is cell type specific and can impact the workload of the secretory machinery. Moreover, cell migration, differentiation or proliferation features can also create the demand for a higher need for protein secretion. Protein secretion fluctuations affect cell homeostasis, particularly cell amino acid, lipid and sugar metabolism and energy consumption. As such, a strong and reliable adaptive system is central for the cell to cope with the increased demand for protein folding in the ER. This adaptive system is named the Unfolded Protein Response (UPR). In this review, we provide specific examples illustrating how the diversification of UPR signals in many human cell types, particularly in secretory cells, could impact typical cancer initiation, tumor development and cancer cell aggressiveness.

The UPR transmits stress signals from the ER lumen to the rest of the cell by three different proteins called PERK, ATF6 and IRE1. PERK (PKR-like endoplasmic reticulum kinase) is a transmembrane protein with a specific kinase activity in its cytosolic domain. Its main substrate is the translation initiation factor eIF2 $\alpha$. Phosphorylation of eIF2 $\alpha$ results in a decrease in translation as well as a preferential translation of key proteins such as CHOP and GADD34, two factors directly involved in the cellular decisions of life or death. The transmembrane protein ATF6 (Activating Transcription Factor 6) is an ER transcription factor. Under stress conditions, ATF6 is exported to the Golgi apparatus, cleaved and released from its membrane attachment by the proteases $\mathrm{S} 1 \mathrm{P}$ and $\mathrm{S} 2 \mathrm{P}$, to play its role as nuclear transcriptional activator. Finally, IRE1 (Inositol Requiring Enzyme 1), an ER resident type 1 transmembrane protein, has two enzymatic activities in its cytosolic domain: a serine/threonine kinase and an endoribonuclease activity. The endoribonuclease activity itself has two distinct molecular functions: i) it participates in the unconventional splicing of the 
XBP1 transcription factor mRNA [4]; ii) it degrades the mRNA of several secreted proteins, a process called RIDD (Regulated IRE1-Dependent Decay of RNA) [5]. The integration of signals from these three molecular pathways leads to a general transcription and translation reorientation, in favor of cell survival. Among the cellular processes regulated, the antioxidant capacity is increased, protein synthesis is decreased and the expression of ER chaperones/ER quality control proteins involved in protein folding (BiP, GRP94, CRT, PDIs) and in misfolded protein degradation is enhanced [6-8]. Finally, if ER homeostasis is not restored, ER stress can trigger apoptosis [9, 10] (Figure 1).

It is well established that differentiated cells such as neurons, blood cells, pancreatic $\beta$ cells, hepatocytes, all require a dedicated secretory pathway with appropriate specialized regulations [11]. In accordance with this, an increasing number of studies have shown a dependency of specific UPR components for the differentiation of particular cell types. For instance, the IRE1-XBP1 branch is required for the differentiation of pancreatic $\beta$ cells, plasma cells, or adipocytes $[12,13,14,15,16]$ and disturbance of the PERK-ATF4 pathway triggers defects in oligodendrocytes, pancreatic and skeletal functions $[17,18,19$, $20,21]$.

\section{A. The "secretory switch" in transformed cells}

Most cancers have to cope with increasing fluxes of proteins through their secretory pathway. This high secretory protein demand is caused by different hallmarks of cancer [2] and comprises all the processes that increase gene expression, in an unspecific manner, such as aneuploidy or the universal amplifier of transcription, MYC [22, 23]. Hence, it is not surprising that aneuploidy was found to be associated to hypersensitivity to conditions interfering with protein synthesis and protein folding in yeast [24] and in human cancer cells [25], and that MYC transformation requires a reliable secretory pathway to mediate its oncogenic potential [26]. Moreover, cell transformation can result in an increase in proliferation and metabolic demand, thereby leading to nutrient (i.e. glucose, amino acids) depletion and subsequent ER stress [27]. This means that during the cell transformation process, a "secretory switch" occurs and provides the transformed cells with novel secretory properties, which will in turn impact on cell homeostasis and interaction with the stroma.

What are the consequences of the "secretory switch" and associated ER stress on tumor-stroma interactions? First, it can lead to microenvironment architecture destabilisation by remodelling of the extracellular matrix (ECM) through changes in ECM components abundance or matrix metalloproteases (MMPs) expression, and consequently, to an increase 
in cancer dissemination and invasion [28, 29]. Second, by modulating messenger (i.e. chemokines, cytokines) or contact/adhesion protein abundance (i.e. membrane receptors, integrins), the "secrotory switch" and associated ER stress can trigger cancer cell proliferation, migration or tumor angiogenesis. Third, it can lead to remodelling of the immune response and ER stress transmission in the tumor microenvironment [30, 31]. Fourth, it can modulate tumor immunogenicity by stimulating surface exposure of ER chaperones such as CRT [2, 32,33 ] (Figure 2).

\section{A.1. UPR involvement in gastrointestinal cancer initiation}

The UPR is a central pathway for intestinal functions and differentiation, and the human gastrointestinal tract represents an interesting example of UPR specialization. This is well illustrated by the immunostaining of UPR components in the normal intestine, which showed that UPR activation occurs in a heterogeneous manner in intestinal cell populations. Indeed, GRP78 abundance appeared high in transit amplifying cells (TA), low in intestinal stem cells (ISC) and heterogenous in Paneth cells [34]. This suggests that the UPR could be induced with intestinal cell differentiation or could represent a pathway driving differentiation. One element supporting the second hypothesis is that activation of the PERK/eIF2 $\alpha$ axis in itself is sufficient to trigger the loss of ISC stemness [34]. Considering that ISCs are thought to represent the cells of origin for most colorectal cancers (CRCs) [35], this suggests that ER stress could have central implication for cancer initiation in the gastrointestinal tract.

Apart from the PERK/eIF $2 \alpha$ arm, specialization of the UPR in the intestine is partly due to the IRE1 branch. Indeed, the gastrointestinal tract is the main tissue where the two IRE1 paralogs, IRE1 $\alpha$ and IRE1 $\beta$ are expressed (in the epithelial cells) [36]. Although the functions of IRE1 $\beta$ are not entirely understood, IRE1 $\beta-/-$ mice showed a role in the control of mucin production in goblet cells [37] and in resistance to chemically induced colitis [36]. Moreover, XBP1 deficiency or expression of XBP1 variants was associated with Crohn's disease and ulcerative colitis [38]. Interestingly, IRE1 $\beta$ and XBP1 deficiency were both associated with increased ER stress and inflammation of the intestine. A more recent report described the association between inflammatory bowel disease and tumorigenesis upon targeted deletion of XBP1 in the intestine [39]. In this model, XBP1 loss in epithelial cells results in an increase in colorectal cancer and colitis-associated cancer. This effect was attributed to an increase in ISC and TA cells, and a dysfunction of Paneth cells. ISC hyperproliferation was linked to increased WNT11 expression in Paneth cells and TA cells hyperproliferation to the activation of an ER stress-dependent interleukin/STAT3 pathway. Interestingly, in this study, a transgenic mouse model presenting a double deletion of XBP1 and IRE1 $\alpha$ was found to not 
present ISC hyperproliferation observed in XBP1 deficient mice. Although one can ask the question of the roles of others components of the UPR, and especially IRE1 $\beta$ in these processes, the authors proposed that IRE1 $\alpha$ is an important mediator of ER stress induced ISC expansion, in an XBP1-independent manner, which might leave room for an instrumental role of RIDD. In addition, XBP1 deletion in Paneth cells revealed that the IRE1 $\alpha-\mathrm{TNF} \alpha / \mathrm{NF}-\kappa \mathrm{B}$ pathway was central for ER stress-induced inflammation [40]. Parallel to these mechanisms, autophagy induced by the PERK/eIF2 $\alpha /$ ATF4 signaling axis partly restrained IRE1 activation and ER stress-induced intestinal inflammation. This was proposed as an explanation for the identification of mutations in autophagy components as risk factors in Crohn's disease [40]. Finally, adding to the role of the UPR in intestinal epithelium, XBP1 was also identified as a susceptibility locus associated with oesophagus squamous cell carcinoma [41] and ER stress was shown to induce epithelial differentiation in precursor cells in the oesophagus [42] and also may be linked to Barett's syndrome [43].

These studies provide good examples of i) how the UPR can fine-tune the entire functions and differentiation of the gastrointestinal epithelia by integrating information from the microenvironment and ii) how deregulation of this molecular pathway (XBP1 deletion) can impact inflammatory bowel disease and gastrointestinal cancer initiation.

\section{A.2. UPR in blood cancers: transformation, progression and drug resistance}

Blood associated cancers represent interesting models in which UPR signals might determine tumor phenotypes. First of all, the expression and activity of UPR components including BiP, IRE1 $\alpha$, BLIMP1, and XBP1 are required for terminal differentiation of B cells into plasma cells and are found overexpressed in plasma cell-derived multiple myeloma (MM). MM evolves from a highly prevalent premalignant condition termed monoclonal gammopathy of undetermined significance (MGUS). A MGUS/MM phenotype was recently reported in transgenic mice with Em-directed expression of the XBP1 spliced isoform (XBP1s). This was corroborated with the aberrant expression of known human MM dysregulated genes and thus implicates XBP1s dysregulation in MM pathogenesis [44]. Interestingly, Cre-mediated and inducible deletion of BiP, BLIMP1 or XBP1 consistently induces cellular stresses and cell death in normal pre-B cells and in pre-B-cell acute lymphoblastic leukemia (ALL) driven by BCR-ABL and NRAS [45]. Moreover, two ALL clinical trials revealed that high XBP1s levels at the time of diagnosis predicted poor outcome. As such, pharmacological inhibition of IRE1-induced selective cell death in patient-derived pre-B ALL cells and significantly prolonged survival of transplanted mice. As a consequence, pre-B ALL cells appeared uniquely vulnerable to ER stress [45]. In a recent study, the Hypoxia Inducible Factor (HIF)- 
$2 \alpha$ was implicated in the engraftment ability of human acute myeloid leukemia (AML) cells and in the maintenance of hematopoietic stem and progenitor cells (HSPCs). The mechanism controling maintenance of HSPCs also involved ER stress signaling as HIF-2 $\alpha$-deficient HSPCs displayed increased production of reactive oxygen species (ROS), which subsequently triggered apoptosis by activation of the UPR [46]. Hence these results might suggest an instrumental role of the UPR in HSPC differentiation program and in maintenance of the AML phenotype. In another model of blood-derived cancer, Chronic Myeloid Leukemia (CML), apoptotic death triggered by the BCR-ABL inhibitor, Imatinib, is activated downstream of ER stress [47]. Moreover, Imatinib resistance in CML K562 cells was bypassed when preventing the activation of the ATF6 arm of the UPR, thus demonstrating the strong interconnection of these pathways in acquisition of tumor cell phenotypes [48].

\section{B. UPR and EMT: an intricate relationship}

Epithelial to Mesenchymal Transition (EMT) enables carcinoma cells to acquire key malignant traits such as migratory and invasion properties, induces stem cell properties and drug resistance $[49,50,51]$. Hallmarks of this transition are repression of epithelial markers, up-regulation of mesenchymal markers and changes in morphology. During EMT, the phenotype of carcinoma cells is largely modified, for example the loss of epithelial polarity and zonula adherens mediated by the down-regulation of E-cadherin. E-cadherin is a cell adhesion protein and its cytosolic domain is associated at the membrane of the cell to $\beta$ catenin, which is a major player of the canonical WNT pathway [52]. Through EMT, diminution of E-cadherin leads to the release of $\beta$-catenin, resulting in its nuclear translocation. In the nucleus, $\beta$-catenin associates with transcription factors of the TCF/LEF family to regulate transcription of genes involved in EMT, migration and invasion. Activation of the UPR has been involved in a growing number of cancers [53], but the link between UPR and EMT has been studied recently in breast cancers. Indeed, recent reports show an interrelationship between UPR signals and EMT, in a context specific manner [54, 55,56$]$.

\section{B.1. Activation of the UPR is instrumental for EMT induction}

This phenomenon was first reported in thyroid cells, in which tunicamycin or thapsigargin triggered signaling by the proto-oncogene tyrosine kinase SRC, caused dedifferentiation through the down-regulation of thyroid specific genes and induced an EMT-like phenotype. This included the change in the organization of the polarized epithelial monolayer, the formation of actin stress fibers, the loss of trans-epithelial resistance, the down-regulation of E-cadherin and the up-regulation of mesenchymal markers such as vimentin, $\alpha$-smooth actin, 
$\alpha 1$ I collagen and SNAI1/SIP1. Moreover the use of PP2, a SRC kinase inhibitor prevented dedifferentiation and EMT, thus confirming the involvement of the SRC pathway [54]. Moreover, the UPR (induced by tunicamycin or overexpression of a variant protein) in alveolar epithelial cells was shown to trigger the SRC and $\beta$-catenin pathways [57]. Again, the use of PP2 also blocked the EMT and maintained the epithelial phenotype. Notably no increase in TGF- $\beta 1$, an important mediator of EMT, was observed in this report. Interestingly, in renal proximal tubular epithelial cells, thapsigargin induced an EMT whereas tunicamycin did not [58]. ER stressors that alter calcium fluxes between the ER lumen and the cytosol such as thapsigargin lead to an increased expression of TDAG51 and TGF- $\beta 1$. TDAG51 interacts with the cytoskeleton and induces shape changes as well as the activation of WNT signaling thereby leading to EMT. As such, overexpression of TDAG51 alone was able to induce an EMT phenotype in HK-2 cells. The serine/cysteine protease inhibitor SCCA1 is deregulated in many cancers associated with poor differentiation and aggressiveness. In mammary epithelial cells (MCF10A), overexpression of SCCA1 induces chronic UPR. This non-lethal chronic UPR activates NF- $\mathrm{BB}$ that leads to IL-6 production, resulting in EMT-like phenotypes [59]. It has been recently reported that IL-6 signaling plays a critical role in driving EMT through cell autonomous inflammation $[60,61]$. In light of these reports, activation of UPR can lead to EMT trough several mechanisms including IL-6, SRC and/or WNT signaling, but how the UPR is triggered, either through alteration of calcium concentrations or increase of improperly folded proteins, might also determine the biological outcome. Thus, one might hypothesize that ER stressed cells enter dedifferentiation/EMT to change their phenotypes and consequently lower ER stress [57].

\section{B.2. EMT induces activation of the UPR in colorectal and breast carcinoma}

Cells subjected to EMT are also known to display an important secretory phenotype notably by changes in ECM protein secretion $[62,63]$. This could represent a cause for ER stress and UPR activation. In colorectal carcinoma cells (SW480, HCT116), stabilization of HIF1 $\alpha$ through $\mathrm{CoCl}_{2}$-mediated inhibition of proline hydroxylase, or serum starvation, induces EMT and the subsequent activation of the UPR [64]. This mechanism is in part dependent upon ZEB-1, which is the main factor for EMT in colorectal carcinoma cells and a transcriptional repressor for E-cadherin $[52,65,66]$. In mammary epithelial cells, EMT induction by TWIST overexpression correlates with PERK constitutive activation [55]. Other branches of the UPR (i.e. IRE1 $\alpha$ and ATF6) were not involved in this process. Interestingly, inhibition of PERK activity attenuated cells' ability to migrate and to form tumor spheres, thereby indicating that PERK might be involved in EMT-dependent cell malignancy. In addition, 
PERK signaling in EMT dedifferentiated cells leads to constitutive activation of NRF2, a master regulator of cellular response to oxidative damage, causing these cells to become chemoresistant through expression of antioxidant enzymes and drug efflux pumps [67, 68, 69]. These results might therefore explain the correlation observed between PERK activation status and highly aggressive and poorly differentiated breast cancer tumors. It is noteworthy that in tubular epithelial cells both EMT and UPR are activated simultaneously through reactive oxygen species (ROS) and SRC kinase-dependent pathways [70].

\section{Targeting UPR as a novel approach to treat EMT chemoresistant cells}

As there is a hierarchical relationship between UPR and EMT it could allow the development of new treatment strategies. Indeed, in diseases where EMT is induced by UPR e.g. lung fibrosis, chronic kidney disease or breast cancer [57, 58, 59] targeting the UPR or the downstream activated pathways (e.g. SRC, WNT) with inhibitors might be an efficient way to prevent cells from undergoing EMT. In vitro, results were already observed with PP2 targeting the SRC kinase and preventing both PC C13 cells (thyroid cells) and alveolar epithelial cells from undergoing an EMT [54, 57 ]. Currently, ER stress drugs are only used to treat multiple myeloma patients [71], however because EMT is associated with chemoresistance and invasiveness $[49,50,51]$, there is a critical need to develop new approaches, therefore it might be very attractive to exploit the ER stress-sensitivity exhibited by cells subjected to EMT [64]. Indeed it was shown that in breast cancer cells several ER stressors such as tunicamycin, thapsigargin, DTT and A23187 render EMT undergoing cells more sensitive to cell death (up to 25 fold for thapsigargin). These treatment could even selectively eliminated EMT undergoing cells when co-cultivated with normal cells [55]. Also targeting the PERK pathway that is constitutively active in breast cancer $[56,72]$ could also be a promising option. Indeed PERK is required for the cells to secrete new extracellular matrix and to enable EMT undergoing cells to invade, metastasize and form tumor spheres. PERK is also responsible for the constitutive activation of NRF2 in EMT undergoing human breast epithelial cells, causing cells to become MDR. Inhibition of PERK caused the decreased expression of 58 of the 142 NRF2 target genes and sensitized cells to chemotherapy. Together these observations suggest that targeting the UPR and its downstream effectors could be a key therapeutic strategy in the treatment of drug-resistant cancer cells.

\section{C.1. UPR control of glioblastoma phenotypes}


Glioblastoma (GBM) is the most common primary brain tumor in humans and remains incurable [73]. Despite the therapeutic efforts made in recent years, mortality is still close to $100 \%$ at 5 years. Different factors are involved in GBM aggressiveness, among which angiogenesis and tumor cell invasion/infiltration are critical [74, 75]. Moreover, the mesenchymal phenotype is another hallmark of tumor aggressiveness in GBM [76, 77]. Remarkably, a single UPR component, IRE1 $\alpha$ appeared to regulate these three features of GBM aggressiveness. Indeed, it was shown that expression of a dominant negative form of IRE1 $\alpha$ triggered a mesenchymal drift in glioblastoma, characterized by modulation of the expression of extracellular matrix, angiogenesis, and inflammation proteins. This is in agreement with other studies reporting IRE1 $\alpha$ coding gene somatic mutations in GBM [78, 79] and ranking IRE1 $\alpha$ as the fifth highest mutated kinase, carrying at least one driver mutation [78]. The mesenchymal drift accompanied by IRE1 $\alpha$ inactivation was due to a set of pathways acting in a synergistically manner. In this model, IRE1 $\alpha$-driven modulation of angiogenesis was attributed to the positive regulation of pro-angiogenic factors such as VEGF-A, IL-1 $\beta$ and IL-6 secretion $[80,81]$ and the cleavage of the mRNA codding for the circadian gene PERIOD1 [82]. Adding to its role in the regulation of angiogenesis, PERIOD1 also regulated IRE1 $\alpha$-dependent GBM infiltration [82]. Another IRE1 $\alpha$ endoribonuclease substrate, the mRNA coding for the extracellular matrix protein SPARC was also found to be involved in modulation of GBM invasion ability in an autocrine fashion [83]. Taken together, these data underline that IRE1 $\alpha$ in itself, can send both intracrine and autocrine signals to control the phenotype, the physiology and the aggressiveness of GBM.

\section{C.2. UPR in triple negative breast cancer}

Triple negative breast cancers (TNBC) represent the most aggressive breast cancer subtype, with high rates of tumor recurrence and poor overall survival [84]. Although the lack of expression of the estrogen, progesterone and HER2 receptors clusters these tumors within the same group, they still comprise heterogeneous and poorly characterized breast cancers with no selective therapy [85]. Recently, a study by Chen and colleagues [86] revealed the contribution of the UPR to TNBC, in particular through the cross-talk with HIF-1 $\alpha$, a transcription factor previously shown to be of particular importance in the hypoxic response in TNBC. Chen and colleagues characterize a new molecular mechanism, XBP1s-dependent HIF-1 $\alpha$ activation in TNBC, thereby indicating potential novel therapeutic strategies mediated through the inhibition of XBP1 in TNBC [87]. These observations could also be linked to the acquisition of a mesenchymal phenotype by breast tumor cells. Indeed, increased expression of XBP1 is associated with the progression of breast cancer and XBP1s is 
significantly over-expressed in matched metastatic tumors, which can act as a major regulator of EMT through SNAIL signaling [88]. Moreover, as autophagy and UPR signaling also appear to be interconnected, combined chloroquine (CQ), a pharmacological inhibitor of autophagy, with other drugs known to act as ER stress enhancers (nelfinavir (an HIV protease inhibitor) and celecoxib (a cyclooxygenase-2 inhibitor) or its non-coxib analog 2,5-dimethylcelecoxib (DMC)) were tested in TNBC. Addition of CQ resulted in synergistic enhancement of tumor cell killing by ER stress aggravators in vitro and in vivo, thus opening novel therapeutic avenues for TNBC [89].

\section{Conclusions and future perspectives}

Collectively, the afore-mentioned information sheds light on the intricate cancer signaling networks into which the UPR is involved. From this analysis it becomes evident that characterizing the UPR status in tumors might not only represent a good predictor of the disease outcome but also constitute an essential toolkit for better defining personalized treatments and following up treatment efficacy. As such, a thorough analysis of the UPR in tumors could be envisioned to firstly select the best and most relevant markers/predictors of tumor characteristics and then secondly to apply the most efficient targeted therapies to those tumors. Needless to say that in this context, therapies targeting the UPR itself could also be of interest either alone or as adjuvant therapies. In conclusion, the specificity of UPR signals and its impact on tumor phenotype represents an interesting avenue to better characterize carcinogenesis but also when documented in patients' tumors will constitute a novel basis for tumor typing and specialized treatments.

\section{Acknowledgements}

We apologize to colleagues whose work was not cited in this review due to space limitation. This work was funded by grants from Institut National du Cancer (INCa) and Ligue Contre le Cancer to EC. ND was supported by a post-doctoral fellowship from Fondation de France. 


\section{References}

[1] Hanahan D, Weinberg RA. Hallmarks of cancer: the next generation. Cell. 2011;144:64674.

[2] Dejeans N, Manie S, Hetz C, Bard F, Hupp T, Agostinis P, et al. Addicted to secrete novel concepts and targets in cancer therapy. Trends Mol Med. 2014;20:242-50.

[3] Garg A, Maes H, van Vliet AR, Agostinis P. Targeting the Hallmarks of Cancer with Therapy-induced Endoplasmic Reticulum (ER) stress. Mol Cell Oncol. 2014;in press.

[4] Yoshida H, Matsui T, Yamamoto A, Okada T, Mori K. XBP1 mRNA is induced by ATF6 and spliced by IRE1 in response to ER stress to produce a highly active transcription factor. Cell. 2001;107:881-91.

[5] Maurel M, Chevet E, Tavernier J, Gerlo S. Getting RIDD of RNA: IRE1 in cell fate regulation. Trends Biochem Sci. 2014;39:245-54.

[6] Lee AH, Iwakoshi NN, Glimcher LH. XBP-1 regulates a subset of endoplasmic reticulum resident chaperone genes in the unfolded protein response. Mol Cell Biol. 2003;23:7448-59.

[7] Harding HP, Zhang Y, Zeng H, Novoa I, Lu PD, Calfon M, et al. An Integrated Stress Response Regulates Amino Acid Metabolism and Resistance to Oxidative Stress National Institute of Environmental Health Sciences. Mol Cell. 2003;11:619-33.

[8] Wu J, Rutkowski DT, Dubois M, Swathirajan J, Saunders T, Wang J, et al. ATF6alpha optimizes long-term endoplasmic reticulum function to protect cells from chronic stress. Dev Cell. 2007;13:351-64.

[9] Walter P, Ron D. The unfolded protein response: from stress pathway to homeostatic regulation. Science. 2011;334:1081-6.

[10] Hetz C, Chevet E, Harding HP. Targeting the unfolded protein response in disease. Nat Rev Drug Discov. 2013;12:703-19.

[11] Rutkowski DT, Hegde RS. Regulation of basal cellular physiology by the homeostatic unfolded protein response. J Cell Biol. 2010;189:783-94.

[12] Reimold AM, Iwakoshi NN, Manis J, Vallabhajosyula P, Szomolanyi-Tsuda E, Gravallese EM, et al. Plasma cell differentiation requires the transcription factor XBP-1. Nature. 2001;412:300-7.

[13] Zhang K, Wong HN, Song B, Miller CN, Scheuner D, Kaufman RJ. The unfolded protein response sensor IRE1alpha is required at 2 distinct steps in B cell lymphopoiesis. J Clin Invest. 2005;115:268-81.

[14] Tsang KY, Chan D, Bateman JF, Cheah KS. In vivo cellular adaptation to ER stress: survival strategies with double-edged consequences. J Cell Sci. 2010;123:2145-54.

[15] Sha H, He Y, Chen H, Wang C, Zenno A, Shi H, et al. The IRE1alpha-XBP1 pathway of the unfolded protein response is required for adipogenesis. Cell Metab. 2009;9:556-64.

[16] Ma Y, Hendershot LM. The role of the unfolded protein response in tumour development: friend or foe? Nat Rev Cancer. 2004;4:966-77.

[17] Delepine M, Nicolino M, Barrett T, Golamaully M, Lathrop GM, Julier C. EIF2AK3, encoding translation initiation factor 2-alpha kinase 3, is mutated in patients with WolcottRallison syndrome. Nat Genet. 2000;25:406-9.

[18] Harding HP, Zeng H, Zhang Y, Jungries R, Chung P, Plesken H, et al. Diabetes mellitus and exocrine pancreatic dysfunction in perk-/- mice reveals a role for translational control in secretory cell survival. Mol Cell. 2001;7:1153-63.

[19] Lin W, Harding HP, Ron D, Popko B. Endoplasmic reticulum stress modulates the response of myelinating oligodendrocytes to the immune cytokine interferon-gamma. J Cell Biol. 2005;169:603-12.

[20] Wang W, Lian N, Li L, Moss HE, Wang W, Perrien DS, et al. Atf4 regulates chondrocyte proliferation and differentiation during endochondral ossification by activating Ihh transcription. Development. 2009;136:4143-53. 
[21] Zhang P, McGrath B, Li S, Frank A, Zambito F, Reinert J, et al. The PERK eukaryotic initiation factor 2 alpha kinase is required for the development of the skeletal system, postnatal growth, and the function and viability of the pancreas. Mol Cell Biol. 2002;22:386474.

[22] Lin CY, Lovén J, Rahl PB, Paranal RM, Burge CB, Bradner JE, et al. Transcriptional Amplification in Tumor Cells with Elevated c-Myc. Cell. 2012;151:56-67.

[23] Nie Z, Hu G, Wei G, Cui K, Yamane A, Resch W, et al. c-Myc Is a Universal Amplifier of Expressed Genes in Lymphocytes and Embryonic Stem Cells. Cell. 2012;151:68-79.

[24] Torres EM, Sokolsky T, Tucker CM, Chan LY, Boselli M, Dunham MJ, et al. Effects of aneuploidy on cellular physiology and cell division in haploid yeast. Science (New York, NY). 2007;317:916-24.

[25] Tang YC, Williams BR, Siegel JJ, Amon A. Identification of aneuploidy-selective antiproliferation compounds. Cell. 2011;144:499-512.

[26] Barna M, Pusic A, Zollo O, Costa M, Kondrashov N, Rego E, et al. Suppression of Myc oncogenic activity by ribosomal protein haploinsufficiency. Nature. 2008;456:971-5.

[27] Huber AL, Lebeau J, Guillaumot P, Petrilli V, Malek M, Chilloux J, et al. p58(IPK)mediated attenuation of the proapoptotic PERK-CHOP pathway allows malignant progression upon low glucose. Mol Cell. 2013;49:1049-59.

[28] Bissell MJ, Hines WC. Why don't we get more cancer? A proposed role of the microenvironment in restraining cancer progression. Nat Med. 2011;17:320-9.

[29] Leung CT, Brugge JS. Outgrowth of single oncogene-expressing cells from suppressive epithelial environments. Nature. 2012;482:410-3.

[30] Mahadevan NR, Rodvold J, Sepulveda H, Rossi S, Drew AF, Zanetti M. Transmission of endoplasmic reticulum stress and pro-inflammation from tumor cells to myeloid cells. Proc Natl Acad Sci U S A. 2011;108:6561-6.

[31] Mahadevan NR, Zanetti M. Tumor stress inside out: cell-extrinsic effects of the unfolded protein response in tumor cells modulate the immunological landscape of the tumor microenvironment. J Immunol. 2011;187:4403-9.

[32] Senovilla L, Vitale I, Martins I, Tailler M, Pailleret C, Michaud M, et al. An immunosurveillance mechanism controls cancer cell ploidy. Science (New York, NY). 2012;337:1678-84.

[33] Luo B, Lee AS. The critical roles of endoplasmic reticulum chaperones and unfolded protein response in tumorigenesis and anticancer therapies. Oncogene. 2013;32:805-18.

[34] Heijmans J, van Lidth de Jeude JF, Koo BK, Rosekrans SL, Wielenga MC, van de Wetering $M$, et al. ER stress causes rapid loss of intestinal epithelial stemness through activation of the unfolded protein response. Cell Rep. 2013;3:1128-39.

[35] Vermeulen L, Snippert HJ. Stem cell dynamics in homeostasis and cancer of the intestine. Nat Rev Cancer. 2014;14:468-80.

[36] Bertolotti A, Wang X, Novoa I, Jungreis R, Schlessinger K, Cho JH, et al. Increased sensitivity to dextran sodium sulfate colitis in IRE1beta-deficient mice. $\mathrm{J}$ Clin Invest. 2001;107:585-93.

[37] Tsuru A, Fujimoto N, Takahashi S, Saito M, Nakamura D, Iwano M, et al. Negative feedback by IRE1beta optimizes mucin production in goblet cells. Proc Natl Acad Sci U S A. 2013;110:2864-9.

[38] Kaser A, Lee A-H, Franke A, Glickman JN, Zeissig S, Tilg H, et al. XBP1 links ER stress to intestinal inflammation and confers genetic risk for human inflammatory bowel disease. Cell. 2008;134:743-56.

[39] Niederreiter L, Fritz TM, Adolph TE, Krismer AM, Offner FA, Tschurtschenthaler M, et al. ER stress transcription factor Xbp1 suppresses intestinal tumorigenesis and directs intestinal stem cells. J Exp Med. 2013;210:2041-56. 
[40] Adolph TE, Tomczak MF, Niederreiter L, Ko HJ, Bock J, Martinez-Naves E, et al. Paneth cells as a site of origin for intestinal inflammation. Nature. 2014;503:272-6.

[41] Wu C, Kraft P, Zhai K, Chang J, Wang Z, Li Y, et al. Genome-wide association analyses of esophageal squamous cell carcinoma in Chinese identify multiple susceptibility loci and gene-environment interactions. Nat Genet. 2012;44:1090-7.

[42] Rosekrans SL, Heijmans J, Buller NV, Westerlund J, Lee AS, Muncan V, et al. ER stress induces epithelial differentiation in the mouse oesophagus. Gut. 2014.

[43] Pohler E, Craig AL, Cotton J, Lawrie L, Dillon JF, Ross P, et al. The Barrett's antigen anterior gradient-2 silences the p53 transcriptional response to DNA damage. Mol Cell Proteomics. 2004;3:534-47.

[44] Carrasco DR, Sukhdeo K, Protopopova M, Sinha R, Enos M, Carrasco DE, et al. The differentiation and stress response factor XBP-1 drives multiple myeloma pathogenesis. Cancer Cell. 2007;11:349-60.

[45] Kharabi Masouleh B, Geng H, Hurtz C, Chan LN, Logan AC, Chang MS, et al. Mechanistic rationale for targeting the unfolded protein response in pre-B acute lymphoblastic leukemia. Proc Natl Acad Sci U S A. 2014;111:E2219-28.

[46] Rouault-Pierre K, Lopez-Onieva L, Foster K, Anjos-Afonso F, Lamrissi-Garcia I, Serrano-Sanchez M, et al. HIF-2alpha protects human hematopoietic stem/progenitors and acute myeloid leukemic cells from apoptosis induced by endoplasmic reticulum stress. Cell Stem Cell. 2013;13:549-63.

[47] Pattacini L, Mancini M, Mazzacurati L, Brusa G, Benvenuti M, Martinelli G, et al. Endoplasmic reticulum stress initiates apoptotic death induced by STI571 inhibition of p210 bcr-abl tyrosine kinase. Leuk Res. 2004;28:191-202.

[48] Higa A, Taouji S, Lhomond S, Jensen D, Fernandez-Zapico ME, Simpson JC, et al. Endoplasmic reticulum stress-activated transcription factor ATF6alpha requires the disulfide isomerase PDIA5 to modulate chemoresistance. Mol Cell Biol. 2014;34:1839-49.

[49] Thiery JP, Acloque H, Huang RY, Nieto MA. Epithelial-mesenchymal transitions in development and disease. Cell. 2009;139:871-90.

[50] Nieto MA, Cano A. The epithelial-mesenchymal transition under control: global programs to regulate epithelial plasticity. Semin Cancer Biol. 2012;22:361-8.

[51] Baum B, Settleman J, Quinlan MP. Transitions between epithelial and mesenchymal states in development and disease. Semin Cell Dev Biol. 2008;19:294-308.

[52] Schmalhofer O, Brabletz S, Brabletz T. E-cadherin, beta-catenin, and ZEB1 in malignant progression of cancer. Cancer Metastasis Rev. 2009;28:151-66.

[53] Clarke HJ, Chambers JE, Liniker E, Marciniak SJ. Endoplasmic reticulum stress in malignancy. Cancer Cell. 2014;25:563-73.

[54] Ulianich L, Garbi C, Treglia AS, Punzi D, Miele C, Raciti GA, et al. ER stress is associated with dedifferentiation and an epithelial-to-mesenchymal transition-like phenotype in PC Cl3 thyroid cells. J Cell Sci. 2008;121:477-86.

[55] Feng YX, Sokol ES, Del Vecchio CA, Sanduja S, Claessen JH, Proia TA, et al. Epithelial-to-mesenchymal transition activates PERK-eIF2alpha and sensitizes cells to endoplasmic reticulum stress. Cancer Discov. 2014;4:702-15.

[56] Del Vecchio CA, Feng Y, Sokol ES, Tillman EJ, Sanduja S, Reinhardt F, et al. Dedifferentiation confers multidrug resistance via noncanonical PERK-Nrf2 signaling. PLoS Biol. 2014;12:e1001945.

[57] Tanjore H, Cheng DS, Degryse AL, Zoz DF, Abdolrasulnia R, Lawson WE, et al. Alveolar epithelial cells undergo epithelial-to-mesenchymal transition in response to endoplasmic reticulum stress. J Biol Chem. 2011;286:30972-80. 
[58] Carlisle RE, Heffernan A, Brimble E, Liu L, Jerome D, Collins CA, et al. TDAG51 mediates epithelial-to-mesenchymal transition in human proximal tubular epithelium. Am J Physiol Renal Physiol. 2012;303:F467-81.

[59] Sheshadri N, Catanzaro JM, Bott A, Sun Y, Ullman E, Chen E, et al. SCCA1/SerpinB3 promotes oncogenesis and epithelial-mesenchymal transition via the unfolded protein response and IL-6 signaling. Cancer Res. 2014.

[60] Gao SP, Mark KG, Leslie K, Pao W, Motoi N, Gerald WL, et al. Mutations in the EGFR kinase domain mediate STAT3 activation via IL-6 production in human lung adenocarcinomas. J Clin Invest. 2007;117:3846-56.

[61] Sansone P, Storci G, Tavolari S, Guarnieri T, Giovannini C, Taffurelli M, et al. IL-6 triggers malignant features in mammospheres from human ductal breast carcinoma and normal mammary gland. J Clin Invest. 2007;117:3988-4002.

[62] Kirk SJ, Cliff JM, Thomas JA, Ward TH. Biogenesis of secretory organelles during B cell differentiation. J Leukoc Biol. 2009;87:245-55.

[63] Fox RM, Hanlon CD, Andrew DJ. The CrebA/Creb3-like transcription factors are major and direct regulators of secretory capacity. J Cell Biol. 2010;191:479-92.

[64] Zeindl-Eberhart E, Brandl L, Liebmann S, Ormanns S, Scheel SK, Brabletz T, et al. Epithelial-mesenchymal transition induces endoplasmic-reticulum-stress response in human colorectal tumor cells. PLoS One. 2014;9:e87386.

[65] Spaderna S, Schmalhofer O, Wahlbuhl M, Dimmler A, Bauer K, Sultan A, et al. The transcriptional repressor ZEB1 promotes metastasis and loss of cell polarity in cancer. Cancer Res. 2008;68:537-44.

[66] Vandewalle C, Van Roy F, Berx G. The role of the ZEB family of transcription factors in development and disease. Cell Mol Life Sci. 2009;66:773-87.

[67] Alam J, Stewart D, Touchard C, Boinapally S, Choi AM, Cook JL. Nrf2, a Cap'n'Collar transcription factor, regulates induction of the heme oxygenase-1 gene. J Biol Chem. 1999;274:26071-8.

[68] Alam J, Wicks C, Stewart D, Gong P, Touchard C, Otterbein S, et al. Mechanism of heme oxygenase- 1 gene activation by cadmium in MCF-7 mammary epithelial cells. Role of p38 kinase and Nrf2 transcription factor. J Biol Chem. 2000;275:27694-702.

[69] Maines MD. Heme oxygenase: function, multiplicity, regulatory mechanisms, and clinical applications. FASEB J. 1988;2:2557-68.

[70] Lee JY, Chang JW, Yang WS, Kim SB, Park SK, Park JS, et al. Albumin-induced epithelial-mesenchymal transition and ER stress are regulated through a common ROS-c-Src kinase-mTOR pathway: effect of imatinib mesylate. Am J Physiol Renal Physiol. 2011;300:F1214-22.

[71] Curran MP, McKeage K. Bortezomib: a review of its use in patients with multiple myeloma. Drugs. 2009;69:859-88.

[72] Hong M, Kim H, Kim I. Ribosomal protein L19 overexpression activates the unfolded protein response and sensitizes MCF7 breast cancer cells to endoplasmic reticulum stressinduced cell death. Biochem Biophys Res Commun. 2014;450:673-8.

[73] Adamson C, Kanu OO, Mehta AI, Di C, Lin N, Mattox AK, et al. Glioblastoma multiforme: a review of where we have been and where we are going. Expert Opin Investig Drugs. 2009;18:1061-83.

[74] Westphal M, Lamszus K. The neurobiology of gliomas: from cell biology to the development of therapeutic approaches. Nat Rev Neurosci. 2011;12:495-508.

[75] Zhong J, Paul A, Kellie SJ, O'Neill GM. Mesenchymal migration as a therapeutic target in glioblastoma. J Oncol. 2010;2010:430142. 
[76] Phillips HS, Kharbanda S, Chen R, Forrest WF, Soriano RH, Wu TD, et al. Molecular subclasses of high-grade glioma predict prognosis, delineate a pattern of disease progression, and resemble stages in neurogenesis. Cancer cell. 2006;9:157-73.

[77] Carro MS, Lim WK, Alvarez MJ, Bollo RJ, Zhao X, Snyder EY, et al. The transcriptional network for mesenchymal transformation of brain tumours. Nature. 2010;463:318-25.

[78] Greenman C, Stephens P, Smith R, Dalgliesh GL, Hunter C, Bignell G, et al. Patterns of somatic mutation in human cancer genomes. Nature. 2007;446:153-8.

[79] Parsons DW, Jones S, Zhang X, Lin JC-H, Leary RJ, Angenendt P, et al. An integrated genomic analysis of human glioblastoma multiforme. Science (New York, NY). 2008;321:1807-12.

[80] Auf G, Jabouille A, Guerit S, Pineau R, Delugin M, Bouchecareilh M, et al. Inositolrequiring enzyme lalpha is a key regulator of angiogenesis and invasion in malignant glioma. Proc Natl Acad Sci U S A. 2010;107:15553-8.

[81] Drogat B, Auguste P, Nguyen DT, Bouchecareilh M, Pineau R, Nalbantoglu J, et al. IRE1 signaling is essential for ischemia-induced vascular endothelial growth factor-A expression and contributes to angiogenesis and tumor growth in vivo. Cancer Res. 2007;67:6700-7.

[82] Pluquet O, Dejeans N, Bouchecareilh M, Lhomond S, Pineau R, Higa A, et al. Posttranscriptional regulation of PER1 underlies the oncogenic function of IREalpha. Cancer Res. 2013;73:4732-43.

[83] Dejeans N, Pluquet O, Lhomond S, Grise F, Bouchecareilh M, Juin A, et al. Autocrine control of glioma cells adhesion and migration through IRE1alpha-mediated cleavage of SPARC mRNA. J Cell Sci. 2012;125:4278-87.

[84] Foulkes WD, Smith IE, Reis-Filho JS. Triple-negative breast cancer. N Engl J Med. 2010;363:1938-48.

[85] Lehmann BD, Bauer JA, Chen X, Sanders ME, Chakravarthy AB, Shyr Y, et al. Identification of human triple-negative breast cancer subtypes and preclinical models for selection of targeted therapies. J Clin Invest. 2011;121:2750-67.

[86] Chen X, Iliopoulos D, Zhang Q, Tang Q, Greenblatt MB, Hatziapostolou M, et al. XBP1 promotes triple-negative breast cancer by controlling the HIF1alpha pathway. Nature. 2014;508:103-7.

[87] Lu Y, Liang FX, Wang X. A synthetic biology approach identifies the mammalian UPR RNA ligase RtcB. Mol Cell. 2014;55:758-70.

[88] Li H, Chen X, Gao Y, Wu J, Zeng F, Song F. XBP1 induces snail expression to promote epithelial- to-mesenchymal transition and invasion of breast cancer cells. Cell Signal. 2014.

[89] Thomas S, Sharma N, Golden EB, Cho H, Agarwal P, Gaffney KJ, et al. Preferential killing of triple-negative breast cancer cells in vitro and in vivo when pharmacological aggravators of endoplasmic reticulum stress are combined with autophagy inhibitors. Cancer Lett. 2012;325:63-71. 


\section{Figures and Legends}

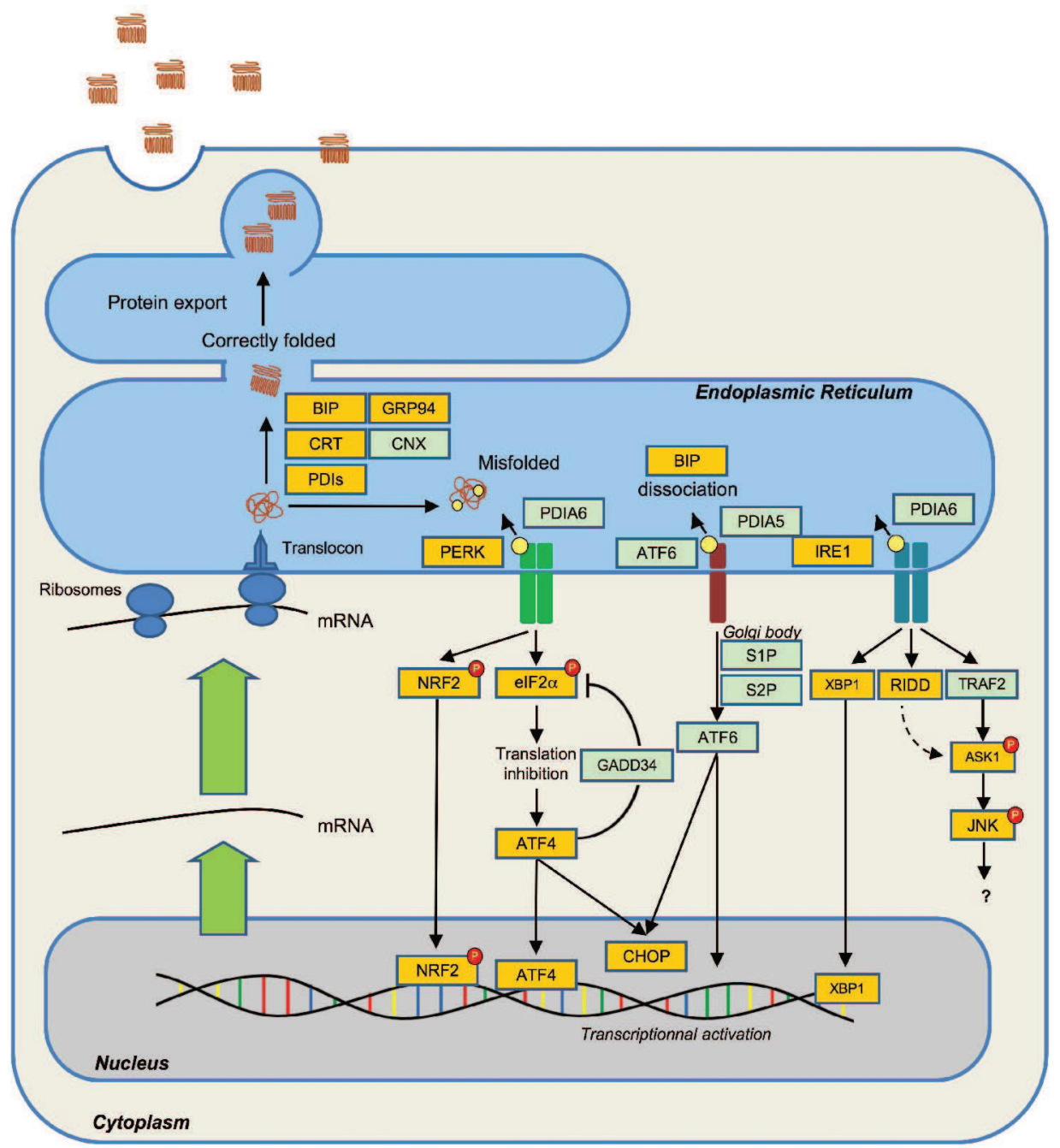

Figure 1: Cancer relevant UPR signaling components - Major UPR signaling modules are drawn. Relevance to cancer is indicated as follows: Orange - proteins directly implicated in the modulation of cancer cell features, including initiation, angiogenesis, inflammation, immunogenicity or resistance. Green - proteins whose modulation or activation is observed in cancer tissues or involved with cancer development or aggressiveness, but whose role in the control of cancer features is not clearly defined. 


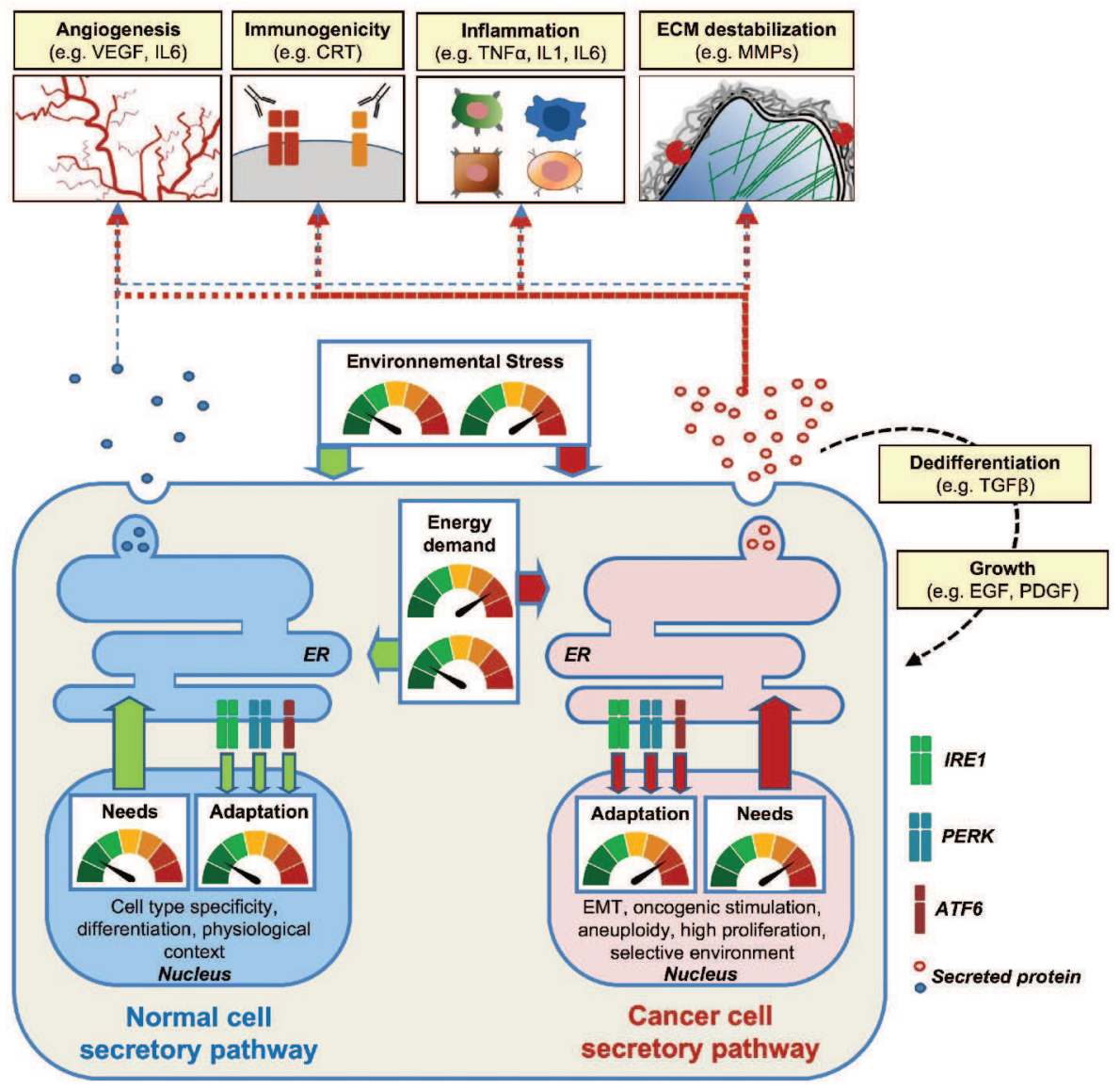

Figure 2: Normal vs. cancer cell secretory pathway control and biological outcomes. In normal cells, the secretory pathway adapts to fluctuation of environmental stresses and intracellular needs, through a complex molecular signaling pathway: the unfolded protein response (UPR). This adaptation program is triggered by three ER transmembrane sensors, namely IRE1, PERK and ATF6. The cell secretory proteins needs vary depending on cell type, differentiation state or on the physiological context. In cancer cells, the secretory pathway is subjected to a strong environmental pressure due to environmental stress factors, such as hypoxia, oxidative stress or chemotherapies, and to oncogenic pressure (e.g. Myc/aneuploidy stimulation of transcription). Furthermore, in these cells, the increase in secretion demand is also dependent on a substantial requirement of energy and amino acid supply. The integration of both intrinsic and extrinsic challenges results in disturbance of the ER homeostasis causing the UPR to be constitutively active in these cells. Disturbance of the secretory pathway will, as a consequence, lead to the modulation of the secretion of proteins important for cancer features such as growth factors and their associated receptors, extracellular matrix proteins, matrix metalloproteases, inflammatory factors, integrins, immunogenic factors or pro angiogenic factors. 